\title{
Switching from IFX originator to biosimilar CT- P13 does not impact effectiveness, safety and immunogenicity in a large cohort of IBD patients
}

Daniela Pugliese , Luisa Guidi , Giuseppe Privitera , Lorenzo Bertani , Barbara Tolusso, Luigi Giovanni Papparella, Simona Maltinti , Clara Di Mario, Sara Onali , Linda Ceccarelli, Gian Lodovico Rapaccini , Franco Scaldaferri, Elisa Gremese , Antonio Gasbarrini , Francesco Costa \& Alessandro Armuzzi

To cite this article: Daniela Pugliese , Luisa Guidi , Giuseppe Privitera , Lorenzo Bertani , Barbara Tolusso , Luigi Giovanni Papparella , Simona Maltinti , Clara Di Mario, Sara Onali , Linda Ceccarelli , Gian Lodovico Rapaccini , Franco Scaldaferri , Elisa Gremese , Antonio Gasbarrini , Francesco Costa \& Alessandro Armuzzi (2020): Switching from IFX originator to biosimilar CT-P13 does not impact effectiveness,safety and immunogenicity in a large cohort of IBD patients, Expert Opinion on Biological Therapy, DOI: 10.1080/14712598.2020.1839045

To link to this article: https://doi.org/10.1080/14712598.2020.1839045

Accepted author version posted online: 19 Oct 2020.

III Article views: 14
Submit your article to this journal 저

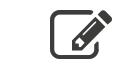


Publisher: Taylor \& Francis \& Informa UK Limited, trading as Taylor \& Francis Group

Journal: Expert Opinion on Biological Therapy

DOI: $10.1080 / 14712598.2020 .1839045$

Switching from IFX originator to biosimilar CT-P13 does not impact effectiveness, safety and immunogenicity in a large cohort of IBD patients

Daniela Pugliese $^{1 *}$, Luisa Guidi ${ }^{1,2}$, Giuseppe Privitera ${ }^{2}$, Lorenzo Bertani ${ }^{3}$, Barbara Tolusso ${ }^{4}$, Luigi Giovanni Papparella ${ }^{1}$, Simona Maltinti $^{3}$, Clara Di Mario ${ }^{4}$, Sara Onali ${ }^{1}$, Linda Ceccarelli ${ }^{5}$, Gian Lodovico Rapaccini ${ }^{1,2}$, Franco Scaldaferri ${ }^{1}$, Elisa Gremese ${ }^{4}$, Antonio Gasbarrini $^{1,2}$, Francesco Costa $^{6}$, Alessandro Armuzzi ${ }^{1,2}$.

*Authors contributed equally

1 CEMAD - IBD UNIT - Unità Operativa Complessa di Medicina Interna e Gastroenterologia, Dipartimento di Scienze Mediche e Chirurgiche, Fondazione Policlinico Universitario "A. Gemelli" IRCCS, Rome, Italy

2 Dipartimento Universitario di Medicina e Chirurgia Traslazionale, Università Cattolica del Sacro Cuore, Rome, Italy

3 University of Pisa, Department of New Technologies and Translational Research in Medicine and Surgery, Pisa, Italy

4 OU Rheumatology Columbus, Fondazione Policlinico Universitario A. Gemelli IRCCS, Rome, Italy

5 Division of Rheumatology, Università Cattolica del Sacro Cuore, Rome, Italy

6 Pisa University Hospital, Department of General Surgery and Gastroenterology, IBD Unit

Corresponding Author:

Professor Alessandro Armuzzi

Fondazione Policlinico Universitario Agostino Gemelli IRCCS

Largo Agostino Gemelli, 1

Rome 00168, Italy

Phone: +390630156265 
Email: alessandro.armuzzi@unicatt.it

\begin{abstract}
Background: Switching from IFX originator to CT-P13 is safe; however, little data on immunogenicity exists.
\end{abstract}

Research design and methods: Consecutive IBD patients on IFX originator were switched to CT-P13 and followed-up for 12 months. Clinical activity, infliximab trough levels (ITLs), anti-drug antibodies (ATIs) and adverse events were recorded at predefined timepoints (baseline, second CT-P13 infusion, 6 and 12 months). The outcomes investigated were immunogenicity, pharmacokinetics, effectiveness and safety.

Results: 119 patients were switched to CT-P13 after a median time with IFX of 5.8 years. No changes in mean ITLs were observed. ATIs were detected in 30 patients (25.2\%): 14 before and 16 after switch. Mean persistent ATIs were significantly higher compared to mean transient ones $(109.74 \mathrm{ng} / \mathrm{mL} \pm 84.70$ vs $18.22 \mathrm{ng} / \mathrm{mL} \pm 11.37, \mathrm{p}<0.001)$, with significantly lower ITLs associated (mean $0.32 \mu \mathrm{g} / \mathrm{mL} \pm 0.6 \mathrm{vs} 3.08 \mu \mathrm{g} / \mathrm{mL} \pm 3.22, \mathrm{p}<0.001$ ). A significant decrease of patients in steroid-fee clinical remission was observed after the switch $(p=0.004)$, with subsequent improvement at 6 months $(p=0.005)$. Eighteen patients $(15.1 \%)$ discontinued IFX, only $6(5 \%)$ for loss of response.

Conclusions: Switching from infliximab originator to CT-P13 seems safe and effective, without differences in immunogenicity. A temporary reduction of clinical benefit after switching could be potentially explained by a "nocebo-effect response".

Key words: Inflammatory Bowel Disease, Infliximab, Pharmacokinetics, Immunogenicity, Trough levels, CT-P13 


\section{Introduction}

Inflammatory bowel diseases (IBD) are chronic conditions, characterized by a relapsingremitting course, requiring lifelong medications to maintain remission and prevent disease relapses and progression ${ }^{1,2}$. Biological drugs have significantly contributed to improve IBD management and patients 'quality of life, but have induced a significant increase in healthcare costs, resulting as the main driver of treatment-related expenses ${ }^{3,4}$. The advent of anti TNF- $\alpha$ biosimilars, after expiration of originators' patents, resulted in considerable cost-savings and increased patients' access to these drugs ${ }^{5}$.

Once a biosimilar has been approved for a specific clinical indication, all others can be extrapolated on a comprehensive comparability exercise ${ }^{6}$. Accordingly, after the registration trials PLANETRA $^{7}$ and PLANETAS ${ }^{8}$ involving patients with rheumatoid arthritis and spondylarthritis respectively, biosimilar infliximab (IFX) CT-P13 has been progressively adopted for patients with IBD both anti TNF- $\alpha$ naïve and experinced ${ }^{9}$. With regard to switching from IFX originator to CT-P13, a randomized, double-blind, non-inferiority controlled trial revealed no efficacy, safety, or immunogenicity issues in a mixed cohort of patients with immune-mediated inflammatory diseases, but the study was underpowered to confirm data for each specific condition, including IBD. Moreover, the primary endpoint was a composite disease worsening endpoint, based on Harvey-Bradshaw Index $(\mathrm{HBI})^{10}$ and Partial Mayo Score (PMS) ${ }^{10}$, never adopted previously ${ }^{11}$.

Conversely, the phase 4 open-label non-inferiority SECURE trial showed that the switching to CT-P13 was safe and well tolerated, with no changes in pharmacokinetics, in a cohort of remitting IBD patients on maintenance therapy with IFX originator for at least 30 weeks and followed-up for 16 weeks after switching ${ }^{12}$. The same figures emerged from preliminary data 
of the ongoing SIMILAR trial presented by Volkers et al. at UEGW 2017 (NCT02452151), including patients in clinical remission on IFX therapy for at least 12 weeks prior to inclusion $^{13}$. In the face of small number of RCTs, several real-life data have shown that switching from IFX originator to CT-P13 is also effective and safe for IBD patients and allows significant cost-saving ${ }^{14-16}$. With regard to immunogenicity, most studies included only the incidence of anti-drug antibodies (ADA), without reporting the titres and the direct effects on safety, pharmacokinetics and efficacy.

Interestingly, it has been reported that the switch from an originator to a biosimilar drug can be associated with a nocebo effect. Nocebo effects are defined as "psychological, physiological, and neurobiological phenomena associated with actual or perceived harm that occur as a consequence of patients' negative expectancies, psychosocial context, and therapeutic environment, not the known pharmacologic actions of treatment". Despite not being extensively studied yet, the nocebo effect might play a meaningful role in the success of a switching program, due to its impact on patients' clinical outcomes. ${ }^{17}$

The aim of our study was to inyestigate the immunogenicity, pharmacokinetics, effectiveness and safety of switching from infliximab originator to biosimilar CT-P13 in a real-life cohort of IBD patients.

\section{PATIENTS AND METHODS}

Consecutive IBD patients from 2 Italian referral centres, on maintenance treatment with IFX originator, were switched to CT-P13 at the time of inclusion and prospectively followed-up for 12 months or until treatment discontinuation, from March 2018 to November 2019. Inclusion criteria were age $\geq 18$-years-old, established IBD diagnosis and being on treatment with IFX originator for at least 6 months. 
The collected baseline data included: gender, age, smoking habit, type and duration of disease, location of IBD according to the Montreal classification ${ }^{18}$, previous and concomitant medications, clinical activity, C-reactive protein (CRP) serum levels and the most recent endoscopic assessment (within maximum 3 months before inclusion), when available. Study visits occurred: one when patients received the second infusion of CT-P13 and then after 6 and 12 months from baseline. At each time point, clinical activity, CRP serum levels and concomitant medications were recorded. Baseline and follow-up clinical activity was measured using Patient-Reported Outcomes (PRO) 2: for UC, stool frequency and rectal bleeding were calculated based on the 3 days before clinical evaluation, while for CD weighted soft stools number and abdominal pain score of the previous 7 days were used. ${ }^{19,20}$ Follow-up endoscopic assessments, whenever performed according to routine clinical practice, were reported. Simple Endoscopic Score for Crohn's Disease (SES-CD) was used for patients with Crohn's Disease (CD) and endoscopic Mayo subscore for those ones with Ulcerative Colitis (UC).

Serum samples were collected at each study visit (last infliximab originator infusion, first CT-P13 infusion, 6 and 12 months) and used to determine IFX Trough Levels (ITLs) and antibodies Towards Infliximab (ATIs). All serum samples were assayed by using enzymelinked immunosorbent drug-tolerant assay (ELISA, Lisa Tracker-Duo ${ }^{\circledR}$ Infliximab, Theradiag, Marne-la-Vallée, France).

The therapeutic reference range for ITLs was established between 3-7 $\mu \mathrm{g} / \mathrm{mL}$. ATI were considered positive according to the pre-specified cut-off of $10 \mathrm{ng} / \mathrm{mL}$ and classified as transient, when undetectable in the subsequent sample, or persistent, when detected in two consecutive samples $^{21}$.

The investigated outcomes were: 1) immunogenicity, that is the incidence of ATIs, their titres and the direct effects on safety, pharmacokinetics and effectiveness 2) effectiveness, in terms 
of persistence in therapy, steroid-free clinical remission and steroid-free biochemical remission at each time-point; and 3) safety of switching from IFX originator to CT-P13.

Steroid-free clinical remission was based on PRO2 and defined as a rectal bleeding score of 0 and a stool frequency $\leq 1$ for $\mathrm{UC}^{19}$ or an abdominal pain score $\leq 1$ and liquid to very soft stool frequency $\leq 1.5$ for $\mathrm{CD}^{20}$, without corticosteroid use within the previous 3 months. Steroidfree biochemical remission was defined as a composite outcome of steroid-free clinical remission with $\mathrm{CRP}<5 \mathrm{mg} / \mathrm{L}$.

Endoscopic remission was defined as SES-CD $\leq 2$ and as an endoscopic Mayo subscore $\leq 1$ for $\mathrm{UC}^{18}$.

All adverse events that occurred during the study period were recorded and categorized as adverse events of interest (AEI), if requiring medical intervention/hospitalization and/or treatment discontinuation (temporary or permanent).

\section{Statistical analysis}

Statistical analysis was performed using IBM SPSS Statistics 26 software. Means with standard deviation (SD) or median with range were used for continuous variables, percentage for discrete ones. To compare continuous variables (TL, ATI, CRP), t-Student test was performed; whereas to compare dichotomous variables (steroid-free clinical remission and biochemical remission) McNemar test was used. Significance level was set at $p<0.05$. Kaplan-Meier survival analysis was performed to estimate persistence in therapy.

\section{Ethical considerations}

The study protocol was approved by the Ethics Committee of the Fondazione Policlinico Universitario A. Gemelli IRCCS, Rome, Italy (ID1262, 21 Jul 2016). Every patient provided written informed consent. The study protocol conforms to the ethical guidelines of the 1975 
Declaration of Helsinki (6th revision, 2008) as reflected in a priori approval by the institution's human research committee.

\section{RESULTS}

\section{Population}

One-hundred and nineteen IBD patients were enrolled (94 CD, 25 UC). Population's characteristics are summarized in table 1. Median duration of disease and of IFX therapy at switch were 12.2 years (range 1.5-41) and 5.8 years (range 0.8-15.8), respectively. At baseline, most of patients was in steroid-free clinical remission (70 of $94 \mathrm{CD}, 74.5 \%$; 14 of 25 UC, 56\%). Seven patients (5.9\%) were on concomitant steroid therapy.

\section{Pharmacokinetics and immunogenicity}

Mean ITLs were: $4.75 \mu \mathrm{g} / \mathrm{mL}( \pm 5.02)$ at baseline, $4.35 \mu \mathrm{g} / \mathrm{mL}( \pm 4.52)$ at the second CTP13 infusion, $4.87 \mu \mathrm{g} / \mathrm{mL}( \pm 4.51)$ at 6 months and $5.07 \mu \mathrm{g} / \mathrm{mL}( \pm 6.36)$ at 12 months, without significant differences ( $\mathrm{p}>0.05$ for all comparisons). (Figure 1)

In the whole cohort: $30(25.2 \%)$ patients had detectable ATIs: 11 persistent, 18 transient and 1 had positive ATIs in 2 non-consecutive samples. Mean persistent ATIs were significantly higher compared to mean transient ones $(109.74 \mathrm{ng} / \mathrm{mL} \pm 84.70$ vs $18.22 \mathrm{ng} / \mathrm{mL} \pm 11.37$, $\mathrm{p}<0.001)$. Patients with persistent ATIs had significantly lower ITLs (mean $0.32 \mu \mathrm{g} / \mathrm{mL} \pm 0.6$ ) compared to transient ones (mean $3.08 \mu \mathrm{g} / \mathrm{mL} \pm 3.22, \mathrm{p}<0.001$ ).

At baseline, 14 patients $(11.8 \%$ ) had positive ATIs (mean $85.88 \mathrm{ng} / \mathrm{mL} \pm 88.87$ ) with mean ITLs below therapeutic range $(1.96 \mu \mathrm{g} / \mathrm{mL} \pm 3.38)$. Among them, 7 patients had persistent detectable ATIs (mean $155.2 \mathrm{ng} / \mathrm{mL} \pm 76$ ) at the second CT-P13 infusion and 7 transient (mean $16.55 \mathrm{ng} / \mathrm{mL} \pm 11.06, \mathrm{p}=0.003$ ). Patients with persistent ATIs had barely statistically 
significant lower ITLs (median $0.14 \mu \mathrm{g} / \mathrm{mL} \pm 0.08$ ) compared to transient ones (median 3.78 $\mu \mathrm{g} / \mathrm{mL} \pm 4.13, \mathrm{p}=0.058)$. Sixteen patients $(13.4 \%)$ developed ATIs after the switch (mean ATIs 21,15 ng/mL \pm 17 ): 8 detectable at the second CT-P13 infusions, 6 at 6 months and 2 at 12 months. Of them, 11 patients had transient ATIs, 4 persistent and 1 patient had positive ATIs in 2 non-consecutive samples. No significant difference between mean transient and persistent ATIs was observed after the switch $(18.54 \mathrm{ng} / \mathrm{mL} \pm 3.54$ vs $18.92 \mathrm{ng} / \mathrm{mL} \pm 3.93$, $\mathrm{p}=0.95)$.

Figure 2 summarizes the outcomes of patients with detectable ATIs.

During follow-up, $13(10.9 \%)$ patients received a dose-escalation (i.e.: more than $5 \mathrm{mg} / \mathrm{kg}$ of infliximab at each infusion and/or interval of 4 or 6 weeks between infusions), based on their clinical activity. Notably, at baseline their mean ITLs $(5.16 \mu \mathrm{g} / \mathrm{mL} \pm 5.65)$ were within the optimal therapeutic range, with only a half of patients ( 7 out of 13 ) with ITLs $<3 \mu \mathrm{g} / \mathrm{mL}$. The majority of patients ( 8 out of 13), had their therapy optimized between 6 and 12 months. By the end of the follow-up, their mean ITLs were $8.75 \mu \mathrm{g} / \mathrm{mL}( \pm 9.16)$ and 4 of them still had ITLs below the therapeutic cut-off. Finally, it is worth mentioning that in this sub-cohort, no patient had positive ATIs at baseline and only one of them developed persistent ATIs during the observation.

\section{Effectiveness}

Cumulative probability of persistence in therapy was $98.3 \%$ and $83.4 \%$ at 6 and 12 months, respectively. (Figure 3) Eighteen patients (15.1\%) discontinued treatment, after a median time of 7.5 months from switch (range 4-12 months). CT-P13 was discontinued because of loss of response in 6 patients (5\%; 3 ATIs-positive, 3 ATIs-negative), sustained clinical 
remission in 9 patients $(7.5 \%$; 6 ATIs positive and 3 ATIs-negative), adverse event in 2 patients (2.4\%; both ATIs-negative) and loss to follow-up in 1 patient ( $0.8 \%$, ATIs negative). Eighty-four patients (70.6\%) were in steroid free-clinical remission at baseline, $73(61.3 \%)$ at the second CT-P13 infusion, 84 at 6 months $(70.6 \%$ of the entire cohort, $73 \%$ of patients still on treatment) and 77 patients $(64.7 \%$ of the entire cohort, $76.23 \%$ of patients still on treatment) at 12 months (figure 4).

A significant drop in the proportion of patients in steroid-fee clinical remission was observed after the switch $(70.6 \%$ vs $61.3 \%, p=0.004)$ and a nearly significant improvement was observed after 6 months $(\mathrm{p}=0.052)$, without the need for any dose-escalation. No other significant difference was observed.

The cumulative probability of maintaining steroid-free clinical remission while on CT-P13 treatment was $68.6 \%$ and $44.4 \%$ at 6 and 12 months, respectively. (Figure 5)

Mean CRP levels were $3.10 \mathrm{mg} / \mathrm{L}( \pm 5.24)$ at baseline, $3.24 \mathrm{mg} / \mathrm{L}( \pm 7.29)$ at second CT-P13 infusion, $3.37 \mathrm{mg} / \mathrm{L}( \pm 5.27)$ at 6 months and $3.56 \mathrm{mg} / \mathrm{dL}( \pm 6.71)$ at 12 months $(\mathrm{p}>0.05$ for all comparisons).

Steroid-free biochemical remission was observed in $66(55.5 \%)$ patients at baseline, 63 (52.9\%) at the second CT-P13 infusion, 62 (52.1\% of the entire cohort) at six months and 63 (52.9) at 12 months ( $>0.05$ for all comparisons).

As far as endoscopic remission is concerned, data are available for a subgroup of 69 of 119 patients (58\%), whose baseline and follow-up endoscopy data were available. Among them, 38 patients $(55.1 \%, 8 \mathrm{UC}, 30 \mathrm{CD})$ were in endoscopic remission before switch and 45 patients $(65.2 \%, 8 \mathrm{UC}, 37 \mathrm{CD} ; \mathrm{p}>0.05)$ after the switch. The median time of endoscopic assessment after the switch was 8 months (range 5-12). Endoscopic worsening after switch was observed in 10 patients $(14.5 \%, 2 \mathrm{UC}, 10 \mathrm{CD})$. 
Each of the 13 abovementioned patients who received dose escalation was not in steroid-free clinical remission at the time of therapy optimization. By the end of the observation period, steroid-free clinical remission was regained in 6 out of $13(46.2 \%)$ patients.

\section{Safety}

In the entire study group, AEI were experienced by 24 patients, but only 3 discontinued treatment due to an AEI: 2 cancers and 1 infusion reaction (Table 2). Infections were the most common (50\%): 6 respiratory infections, 3 urogenital and 3 herpes-simplex reactivations. Infusion reactions occurred in 5 patients $(4.2 \%, 2$ ATIs positive, mean 16.25 $\mathrm{ng} / \mathrm{mL} \pm 4.24$ and 3 ATIs negative) and five patients (4.2\%, ATIs negative) experienced a flare of pre-existing psoriasis or arthritis. Two patients were diagnosed with cancer: a 66year-old man with prostate cancer and a 55-year man with rectum cancer.

\section{DISCUSSION}

Switching from IFX originator to its biosimilar CT-P13 is widely considered to be safe and effective for patients with IBD and has been routinely employed in clinical practice. $^{22}$ However, the majority of evidence comes from observational studies, most of which are limited by small sample size and relatively short follow-up period. Moreover, immunogenicity assessment included only the incidence of new ADA, without reporting the titres, the features (transient vs persistent) and the direct effects on pharmacokinetic, efficacy and safety. ${ }^{23-28}$. 
Our study reported data of 119 IBD patients (94 with CD) on maintenance therapy with IFX originator (median duration 5.8 years, range $0.8-15.8$ ) who were switched to CT-P13 and prospectively followed-up to 12 months.

Therapeutic drug monitoring (TDM) was conducted along the study, showing substantial stability of mean infliximab ITLs throughout the observation period, always within the therapeutic range. In our cohort, the rate of immunogenicity was $25.2 \%$, apparently quite higher compared to other previous studies ${ }^{12,23,24,28,29}$. However, almost half of our patients (14 of $30,46.6 \%$ ) had detectable ATIs before switch and this could be explained by the fact that a routine proactive TDM approach is not performed in our hospital. Moreover, only 11 patients had persistent ATIs (7 from baseline and 4 after switch), while the remaining were transient and apparently not influencing pharmacokinetic, efficacy and safety. Conversely, persistent ATIs were associated with lower and more frequently below therapeutic range ITLs compared to transient ones ( $\mathrm{p}<0.001$ ). In our study, we adopted $10 \mathrm{ng} / \mathrm{mL}$ as reference cut-off for ATI-positivity, according to the manufacturer's instructions and available therapeutic algorithms from current literature. Accordingly, in a scenario of loss response to IFX and concomitant undetectable ITLs, patients should be switched to a different anti-TNF $\alpha$ drug $^{30-}$ ${ }^{32}$. However, in our cohort, we observed that most (16/19, 84.2\%) of ATIs with a titre ranging from 10 and $40 \mathrm{ng} / \mathrm{mL}$ were transient and not detectable at the following assessments. Based on these observations, it could be suggested, also in the context of loss of response, to repeat the assessment in case of ATI levels between 10 and $40 \mathrm{ng} / \mathrm{mL}$ and subtherapeutic ITLs, in order to avoid inappropriate therapy discontinuation.

In one patient with persistent baseline ATIs, we observed subsequent negativization at 6- and 12-months assessments. Whether this negativization depends on some differences in the molecular structure of the two products or is just casual cannot be inferred. 
Detection of nil ITLs \pm ATIs in patients with long-term remission has been previously identified as a predictor of lower rate of disease relapse upon treatment discontinuation ${ }^{33,34}$. Overall, we decided to stop IFX only in 9 patients with long-term clinical remission: $6 \mathrm{CD}$ with persistent positive ATIs and 3 UC patients with ATIs negative. As for the last group, mesalamine was chosen as maintenance therapy after IFX discontinuation, 5 out of 6 ATIs positive patients with $\mathrm{CD}$, already exposed to thiopurines and with history of surgery, were switched to a second biological therapy ( 4 adalimumab and 1 ustekinumab). This can be explained by the habit in our hospitals to maintain long-term biological therapy in this category of patients.

We did not adopt a pro-active TDM approach ${ }^{35}$ and did not increase the dose of IFX in case of subtherapeutic TL without ATIs for patients in stable clinical remission. During follow-up, dose-escalation was performed, according to clinical judgement, in $13(10.9 \%)$ patients who were not in steroid-free clinical remission: this allowed to regain steroid-free clinical remission in 6 of these patients, in parallel with a raise in mean ITLs. The rate of optimizations registered in our cohort is considerably lower than those reported in other experiences. ${ }^{36,37}$ This could be potentially explained by the fact that those studies included patients who just started infliximab therapy, while our cohort had a long duration of infliximab therapy before enrolment (median 5.8 years), therefore some of our patients had already been optimized before baseline.

In our cohort, the cumulative probability of persistence in therapy at 6 and 12 months after switch was $98.3 \%$ and $83.4 \%$, respectively, in line with other experiences reported in literature $^{38}$. We recorded a rate of discontinuation for loss of response of $5 \%$ ( 6 patients, 3 ATI-positive and 3 ATI-negative) at 1 year, which is congruent with that expected with $\mathrm{IFX}^{39}$. 
The proportion of patients in steroid-free clinical remission significantly decreased $(70.6 \% \mathrm{vs}$ $61.3 \%, p=0.004)$ after switch, but slightly improved 6 months later $(61.3 \%$ vs $84 \%, p=0.052)$. Conversely, mean CRP levels remained stable throughout the observation period. In our opinion, this can be explained by a "nocebo-effect response" ${ }^{, 7,40}$. Most patients, in fact, especially those ones with durable clinical remission, can be afraid of switching from originator to biosimilar IFX and experience an unfavourable therapeutic effect. The definition of steroid-free clinical remission based on $\mathrm{PRO} 2$ allows a more comprehensive perception of patients' insight and avoid physicians' interpretation of data ${ }^{41}$. Anxiety associated with a perceived "change of therapy" might be held responsible for the observed symptomatic worsening ${ }^{5}$. Accordingly, the relation between patients and health-care providers is crucial for the management of the nocebo effect. ${ }^{42}$ Whether the nocebo effect can be reversed cannot be inferred based on our results, but it can be speculated that patients' reassurance after switch might help preventing the main adverse outcomes associated with the nocebo effect (such as loss of response or adverse events leading to treatment discontinuation). ${ }^{43}$

Twenty-four (20.2\%) patients experienced an AEI during follow-up, 3 of whom had to withdraw CT-P13. These findings are in line with previous experiences with IFX switch, ${ }^{38}$ without additional safety signals.

\section{CONCLUSIONS}

In our cohort of IBD patients, switching from IFX originator to CT-P13 did not have significant impact on safety, effectiveness and pharmacokinetics. Notably, we reported a slight worsening of clinical activity after the switch that could be ascribed to a transient nocebo effect. Moreover, this is, to the best of our knowledge, the first study to present ATIs titres after switch to infliximab biosimilar and discriminate between transient and persistent ones. 
However, our study has some significant limitations: primarily it did not include a control arm. Second, we did not have data on faecal calprotectin levels, as its dosage is not routinely performed at our hospital. Third: endoscopic assessment was not available for each patient. At last, the study is underpowered to detect possible differences between CD and UC.

Comprehensively, the findings of our study further support the suitability of the switch to CT-P13 and give new insights on the interpretation of ATIs titres when performing proactive TDM.

\section{FUNDING}

This paper is not funded.

\section{DECLARATION OF INTERESTS}

D Pugliese received speaker fees from AbbVie, MSD, Takeda, Janssen and Pfizer. L Guidi has received consultancy and/or speaker fees from AbbVie, Janssen, MSD, Mundipharma, Takeda, Vifor Pharma and Zambon. $G$ Privitera has received consultancy fees from Alphasigma. S Onali has received speaker fees from Abbvie, Takeda, Amgen and Norgine. E Gremese has received fees for consultancy and/or lectures from AbbVie, Bristol-Myers Squibb, Celgene, Janssen, MSD, Lilly, Mundipharma, Novartis, Pfizer, Roche, Sandoz, Sanofi, UCB. A Gasbarrini reports personal fees for consultancy for Eisai S.r.l., 3PSolutions, Real Time Meeting, Fondazione Istituto Danone, Sinergie S.r.l. Board MRGE, and Sanofi S.p.A, personal fees for acting as a speaker for Takeda S.p.A, AbbVie, and Sandoz S.p.A, and personal fees for acting on advisory boards for VSL3 and Eisai. A Armuzzi has received consulting and/or advisory board fees from AbbVie, Allergan, Amgen, Biogen, Bristol-Myers Squibb, Celgene, Celltrion, Ferring, Janssen, Lilly, MSD, Mylan, Pfizer, Samsung Bioepis, Sandoz, Takeda; lecture and/or speaker bureau fees from AbbVie, Amgen, Biogen, Ferring, Janssen, MSD, Mitsubishi-Tanabe, Nikkiso, Pfizer, Sandoz, Samsung Bioepis, Takeda; and research grants from MSD, Pfizer, Takeda. The authors have no other relevant affiliations or financial involvement with any organization or entity with a financial interest in or financial conflict with the subject matter or materials discussed in the manuscript apart from those disclosed.

\section{Reviewer Disclosures}

Peer reviewers on this manuscript have no relevant financial relationships or otherwise to disclose.

\section{REFERENCES}


1. Torres J, Bonovas S, Doherty G, et al. ECCO Guidelines on Therapeutics in Crohn's Disease: Medical Treatment. J Crohns Colitis 2020; 14: 4-22.

2. Harbord M, Eliakim R, Bettenworth D, et al. Third European evidence-based consensus on diagnosis and management of ulcerative colitis. Part 2: Current management. J Crohn's Colitis 2017; 11: 769-784.

3. Paschos P, Katsoula A, Salanti G, et al. Systematic review with network meta-analysis: the impact of medical interventions for moderate-to-severe ulcerative colitis on healthrelated quality of life. Aliment Pharmacol Ther 2018; 48: 1174-1185.

4. van der Valk ME, Mangen M-JJ, Severs M, et al. Evolution of Costs of Inflammatory Bowel Disease over Two Years of Follow-Up. PLoS One 2016; 11: e0142481.

5. Armuzzi A, Bouhnik Y, Cummings F, et al. Enhancing treatment success in inflammatory bowel disease: Optimising the use of anti-TNF agents and utilising their biosimilars in clinical practice. Dig Liver Dis. Epub ahead of print June 2020. DOI: 10.1016/j.dld.2020.06.008.

6. Weise M, Kurki P, Wolff-Holz E, et al. Biosimilars: The science of extrapolation. Blood 2014; 124: 3191-3196.

7. Yoo DH, Hrycaj P, Miranda P, et al. A randomised, double-blind, parallel-group study to demonstrate equivalence in efficacy and safety of CT-P13 compared with innovator infliximab when coadministered with methotrexate in patients with active rheumatoid arthritis: The PLANETRA study. Ann Rheum Dis 2013; 72: 1613-1620.

8. Park W, Hrycaj P, Jeka S, et al. A randomised, double-blind, multicentre, parallelgroup, prospective study comparing the pharmacokinetics, safety, and efficacy of CTP13 and innovator infliximab in patients with ankylosing spondylitis: The PLANETAS study. Ann Rheum Dis 2013; 72: 1605-1612.

9. Gecse KB, Lovász BD, Farkas K, et al. Efficacy and Safety of the Biosimilar 
Infliximab CT-P13 Treatment in Inflammatory Bowel Diseases: A Prospective, Multicentre, Nationwide Cohort. J Crohn's Colitis 2016; 133-140.

10. Sturm A, Maaser C, Calabrese E, et al. Ecco-esgar guideline for diagnostic assessment in ibd part 2: Ibd scores and general principles and technical aspects. J Crohn's Colitis 2019; 13: 273-284E.

11. Jørgensen KK, Olsen IC, Goll GL, et al. Switching from originator infliximab to biosimilar CT-P13 compared with maintained treatment with originator infliximab (NOR-SWITCH): a 52-week, randomised, double-blind, non-inferiority trial. Lancet 2017; 389: 2304-2316.

12. Strik AS, van de Vrie W, Bloemsaat-Minekus JPJ, et al. Serum concentrations after switching from originator infliximab to the biosimilar CT-P13 in patients with quiescent inflammatory bowel disease (SECURE): an open-label, multicentre, phase 4 non-inferiority trial. Lancet Gastroenterol Hepatol 2018; 3: 404-412.

13. UEG - United European Gastroenterology, https://ueg.eu/library/similar-trial-efficacyof-infliximab-biosimilar-compared-to-infliximab-biological-in-patients-withinflammatory-bowel-disease-in-remission-a-randomized-controlled-double-blindphase-4-noninferiority-trial/154447 (accessed 25 June 2020).

14. Bernard EJ, Fedorak RN, Jairath V. Systematic Review: Non-medical Switching of Infliximab to CT-P13 in Inflammatory Bowel Disease. Dig Dis Sci. Epub ahead of print 2020. DOI: 10.1007/s10620-019-06036-0.

15. A A, G F, A V, et al. The PROSIT Cohort of Infliximab Biosimilar in IBD: A Prolonged Follow-up on the Effectiveness and Safety Across Italy. Inflamm Bowel Dis; 25. Epub ahead of print 2019. DOI: 10.1093/IBD/IZY264.

16. Fiorino G, Manetti N, Armuzzi A, et al. The PROSIT-BIO Cohort: A Prospective Observational Study of Patients with Inflammatory Bowel Disease Treated with 
Infliximab Biosimilar. In: Inflammatory Bowel Diseases. Oxford University Press, pp. $233-243$.

17. Colloca L, Panaccione R, Murphy TK. The clinical implications of nocebo effects for biosimilar therapy. Front Pharmacol 2019; 10: 1-11.

18. Maaser C, Sturm A, Vavricka SR, et al. ECCO-ESGAR Guideline for Diagnostic Assessment in IBD Part 1: Initial diagnosis, monitoring of known IBD, detection of complications. J Crohn's Colitis 2019; 13: 144-164.

19. Jairath V, Khanna R, Zou GY, et al. Development of interim patient-reported outcome measures for the assessment of ulcerative colitis disease activity in clinical trials. Aliment Pharmacol Ther 2015; 42: 1200-1210.

20. Khanna R, Zou G, D’Haens G, et al. A retrospective analysis: The development of patient reported outcome measures for the assessment of Crohn's disease activity. Aliment Pharmacol Ther 2015; 41: 77-86.

21. Steenholdt C, Bendtzen K, Brynskov J, et al. Cut-off levels and diagnostic accuracy of infliximab trough levels and anti-infliximab antibodies in Crohn's disease. Scand J Gastroenterol 2011; 46: 310-318.

22. Fiorino G, Caprioli F, Daperno M, et al. Use of biosimilars in inflammatory bowel disease: a position update of the Italian Group for the Study of Inflammatory Bowel Disease (IG-IBD). Dig Liver Dis 2019; 51: 632-639.

23. Bronswijk M, Moens A, Lenfant M, et al. Evaluating Efficacy, Safety, and Pharmacokinetics after Switching from Infliximab Originator to Biosimilar CT-P13: Experience from a Large Tertiary Referral Center. Inflamm Bowel Dis 2020; 26: 628634.

24. Smits LJT, Grelack A, Derikx LAAP, et al. Long-Term Clinical Outcomes After Switching from Remicade ${ }^{\circledR}$ to Biosimilar CT-P13 in Inflammatory Bowel Disease. 
Dig Dis Sci 2017; 62: 3117-3122.

25. Chaparro M, Garre A, Guerra Veloz MF, et al. Effectiveness and safety of the switch from remicade ${ }^{\circledR}$ to CT-P13 in patients with inflammatory bowel disease. J Crohn's Colitis 2019; 13: 1380-1386.

26. Guiotto C, Italia A, Lavagna A, et al. Switching from infliximab originator to a first biosimilar is safe and effective. Results of a case-control study with drug levels and antibodies evaluation. Dig Liver Dis 2019; 51: 1117-1122.

27. Ho SL, Niu F, Pola S, et al. Effectiveness of Switching from Reference Product Infliximab to Infliximab-Dyyb in Patients with Inflammatory Bowel Disease in an Integrated Healthcare System in the United States: A Retrospective, Propensity ScoreMatched, Non-Inferiority Cohort Study. BioDrugs 2020; 34: 395-404.

28. Razanskaite V, Bettey M, Downey L, et al. Biosimilar Infliximab in Inflammatory Bowel Disease: Outcomes of a Managed Switching Programme. J Crohns Colitis 2017; 11: 690-696.

29. Høivik ML, Buer LCT, Cvancarova M, et al. Switching from originator to biosimilar infliximab-real world data of a prospective 18 months follow-up of a single-centre IBD population. Scand J Gastroenterol 2018; 53: 692-699.

30. Steenholdt C, Brynskov J, Thomsen OØ, et al. Individualised therapy is more costeffective than dose intensification in patients with Crohn's disease who lose response to anti-TNF treatment: A randomised, controlled trial. Gut 2014; 63: 919-927.

31. Yanai H, Lichtenstein L, Assa A, et al. Levels of drug and antidrug antibodies are associated with outcome of interventions after loss of response to infliximab or adalimumab. Clin Gastroenterol Hepatol 2015; 13: 522-530.e2.

32. Guidi L, Pugliese D, Tonucci TP, et al. Therapeutic drug monitoring is more costeffective than a clinically based approach in the management of loss of response to 
infliximab in inflammatory bowel disease: An observational multicentre study. $J$ Crohn's Colitis 2018; 12: 1079-1088.

33. Ben-Horin S, Chowers Y, Ungar B, et al. Undetectable anti-TNF drug levels in patients with long-term remission predict successful drug withdrawal. Aliment Pharmacol Ther 2015; 42: 356-364.

34. Louis E, Mary JY, Verniermassouille G, et al. Maintenance of remission among patients with Crohn's disease on antimetabolite therapy after infliximab therapy is stopped. Gastroenterology 2012; 142: 63-70.e5.

35. Vande Casteele N, Ferrante M, Van Assche G, et al. Trough concentrations of infliximab guide dosing for patients with inflammatory bowel disease.

Gastroenterology 2015; 148: 1320-1329.e3.

36. Taxonera C, Olivares D, Mendoza JL, et al. Need for infliximab dose intensification in Crohn's disease and ulcerative colitis. World J Gastroenterol 2014; 20: 9170-9177.

37. O’Donnell S, Stempak JM, Steinhart AH, et al. Higher Rates of Dose Optimisation for Infliximab Responders in Ulcerative Colitis than in Crohn's disease. J Crohns Colitis 2015; 9: 830-836.

38. Ebada MA, Elmatboly AM, Ali AS, et al. An updated systematic review and metaanalysis about the safety and efficacy of infliximab biosimilar, CT-P13, for patients with inflammatory bowel disease. Int J Colorectal Dis 2019; 34: 1633-1652.

39. Allez M, Karmiris K, Louis E, et al. Report of the ECCO pathogenesis workshop on anti-TNF therapy failures in inflammatory bowel diseases: Definitions, frequency and pharmacological aspects. J Crohn's Colitis 2010; 4: 355-366.

40. Boone NW, Liu L, Romberg-Camps MJ, et al. The nocebo effect challenges the nonmedical infliximab switch in practice. Eur J Clin Pharmacol 2018; 74: 655-661.

41. Peyrin-Biroulet L, Sandborn W, Sands BE, et al. Selecting Therapeutic Targets in 
Inflammatory Bowel Disease (STRIDE): Determining Therapeutic Goals for Treat-toTarget. Am J Gastroenterol 2015; 110: 1324-1338.

42. Pouillon L, Danese S, Hart A, et al. Consensus report: clinical recommendations for the prevention and management of the nocebo effect in biosimilar-treated IBD patients. Aliment Pharmacol Ther 2019; 49: 1181-1187.

43. Odinet JS, Day CE, Cruz JL, et al. The Biosimilar Nocebo Effect? A Systematic Review of Double-Blinded Versus Open-Label Studies. J Manag care Spec Pharm 2018; 24: 952-959. 
MEAN ITLS

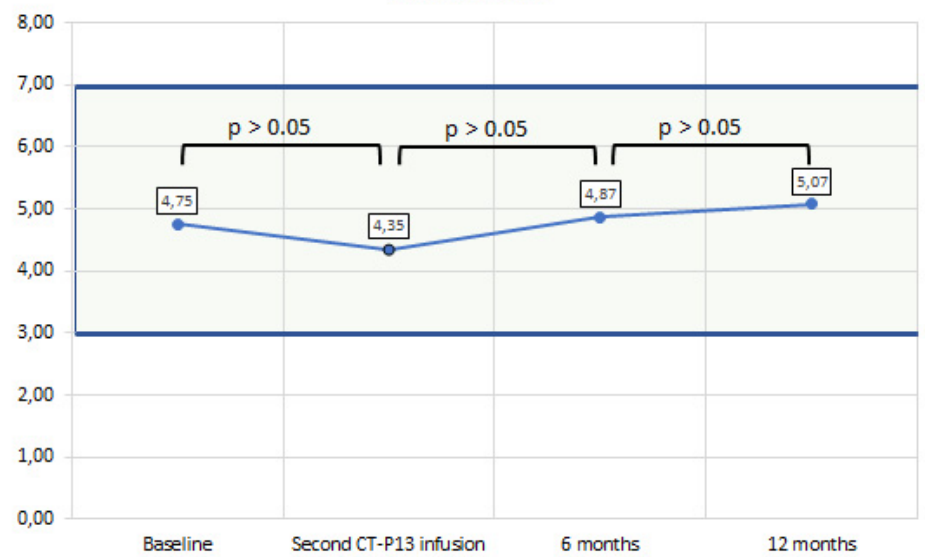

Figure 1 


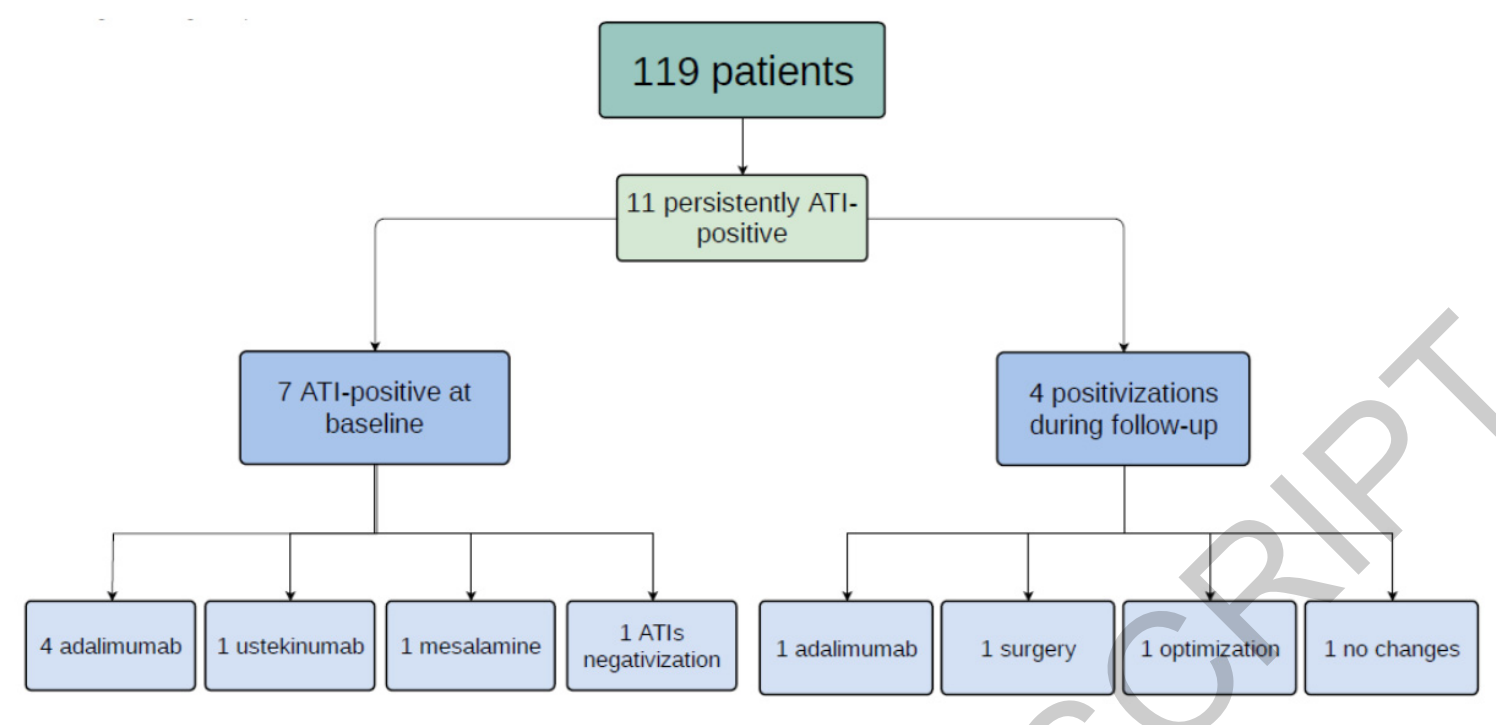

Figure 2 


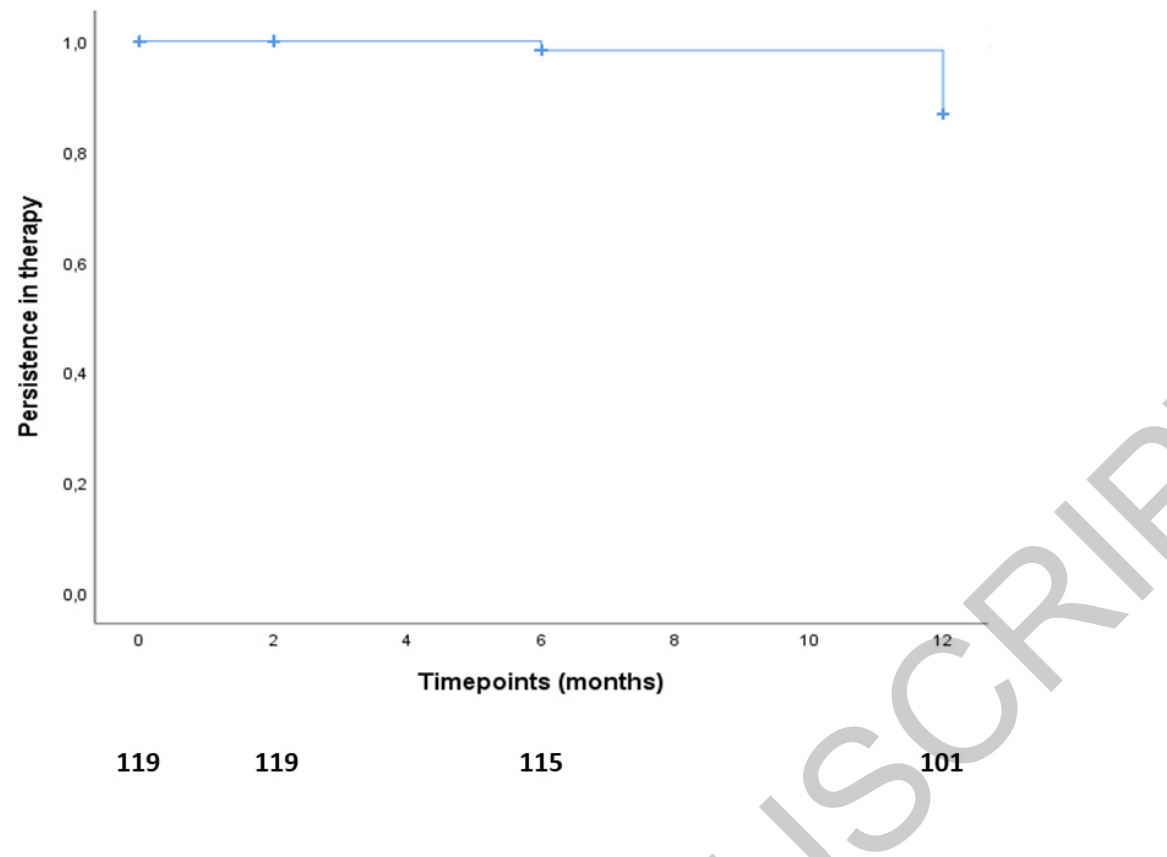

Figure 3 


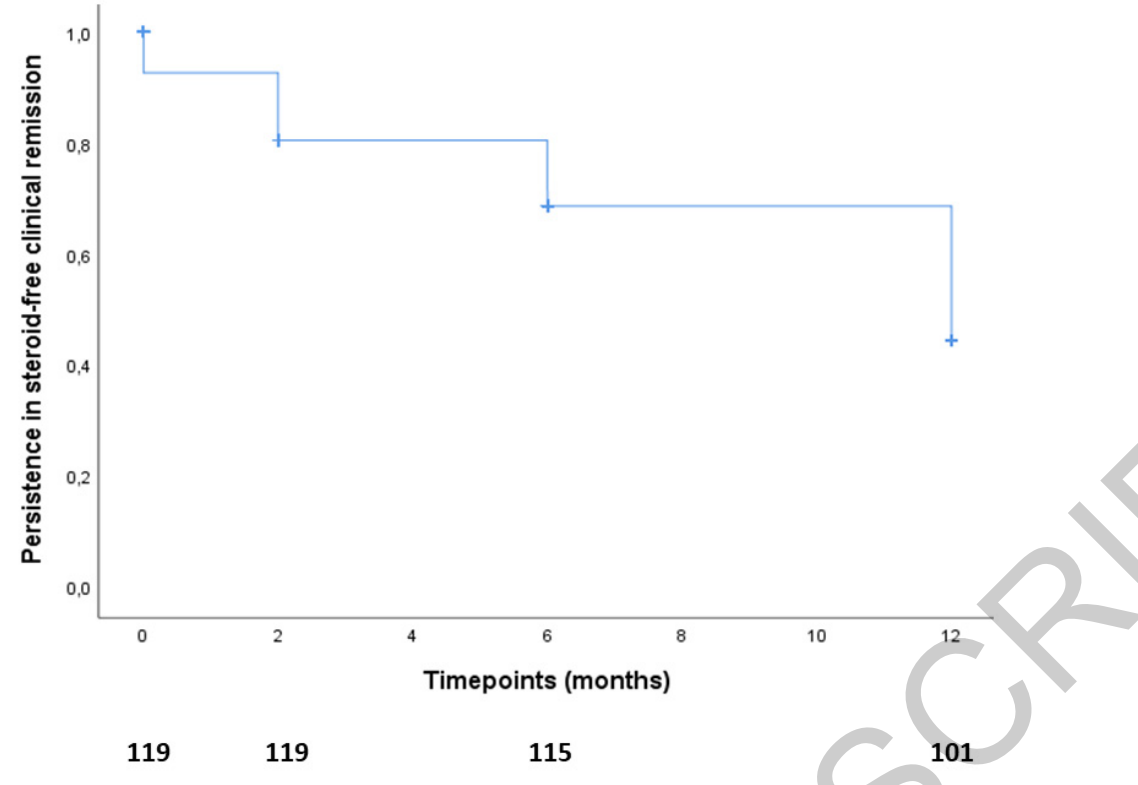

Figure 4 


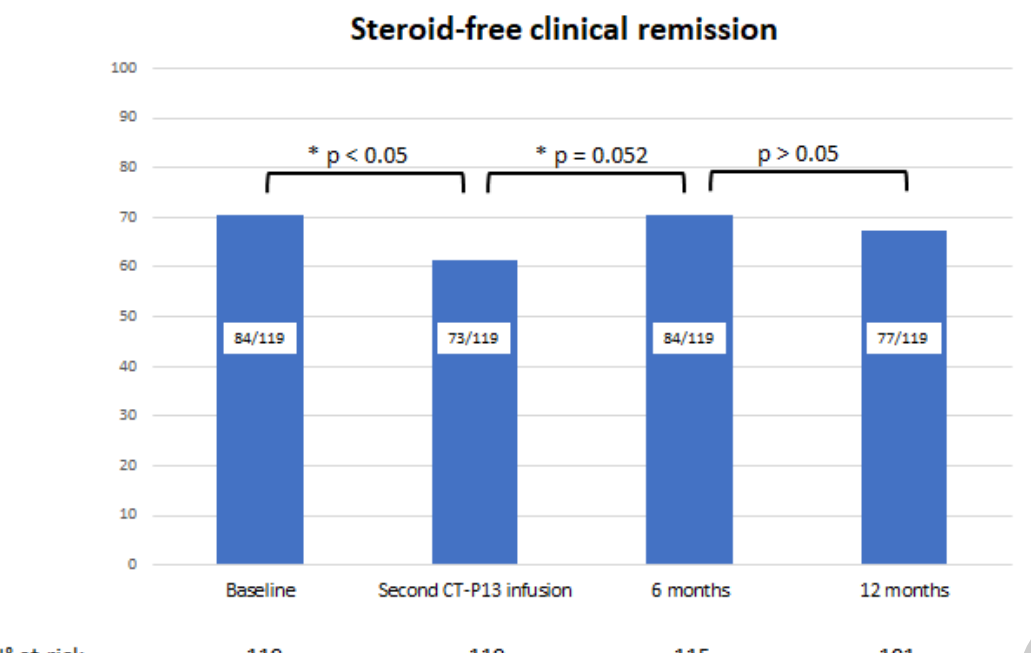

Figure 5 
Table 1. Baseline characteristics

\section{CARATTERISTICHE DEI PAZIENTI AL BASELINE}

Number of patients, $\mathbf{n}$

Female, $\mathrm{n}(\%)$

Age, years, median

Smokers, $\mathbf{n}(\%)$

Duration of disease, years, median (range)

$12.2(1.5-41)$

$\mathrm{N}^{\circ}$ of CD patients (\%)

Localization (\% in CD pts)

L1

$26(27.7)$

L2

L4

Behaviour (\% in CD pts)

B1

B2

B3

Perianal disease (\% in CD pts)

$\mathrm{N}^{\circ}$ of UC patients (\%)

Localization (\% in UC pts)

E1

E2

E3

Clinical activity CD (HBI), $n$ (\% in CD pts)

$<5$

5-7

70 (74.5)

$22(23.4)$

$2(2.1)$

8-16

Clinical activity UC (PMS), $n$ (\% in UC pts)

$<2$

Previous immunosuppressive therapy (\%)

Duration of Infliximab therapy, median, years (range)

Concomitant immunosuppressive therapy, $n$ (\%)

Concomitant steroid therapy, $\mathbf{n}(\%)$

CRP, $\mathrm{mg} / \mathrm{dl}$, mean (SD)

Pts: Patients; CD: Crohn's Disease; UC: Ulcerative Colitis; HBI: Harvey-Bradshaw-Index;

PMS: Partial Mayo Score; CRP: C-Reactive Protein; SD: Standard Deviation.

Table 2. Adverse events of interest 


\begin{tabular}{|c|l|}
\hline Infections & $\mathbf{1 2}(\mathbf{1 0 )}$ \\
Respiratory & $6(5)$ \\
Urogenital & $3(2.5)$ \\
HSV reactivations & $3(2.5)$ \\
\hline Allergic/Paradoxical reactions & $\mathbf{1 0}(\mathbf{8 . 4 )}$ \\
Infusion reactions & $5(4.2)$ \\
New-onset/Relapse arthritis & $3(2.5)$ \\
New-onset/Relapse psoriasis & $2(1.6)$ \\
Neoplastic diseases & $\mathbf{2 ( 1 . 6 )}$ \\
Prostate cancer & $1(0.8)$ \\
Rectum cancer & $1(0.8)$ \\
\hline HSV: Herpes-Simplex Virus. & \\
\hline
\end{tabular}

